\title{
Synergistic bactericidal activity of chlorhexidine- loaded, silver-decorated mesoporous silica nanoparticles
}

This article was published in the following Dove Press journal:

International Journal of Nanomedicine

9 May 2017

Number of times this article has been viewed

\author{
Meng-meng Lu,' Qiu-jing \\ Wang, ${ }^{2}$ Zhi-min Chang, ${ }^{3}$ \\ Zheng Wang, ${ }^{3}$ Xiao Zheng, ${ }^{4}$ \\ Dan Shao, ${ }^{3,4}$ Wen-fei Dong, ${ }^{3}$ \\ Yan-min Zhou' \\ 'Department of Dental Implantology, \\ Jilin Province Key Laboratory of \\ Tooth Development and Bone \\ Remodeling, School and Hospital of \\ Stomatology, ${ }^{2}$ Experimental Center \\ of Functional Sciences, College \\ of Basic Medical Sciences, Jilin \\ University, Changchun, ${ }^{3}$ Chinese \\ Academy of Sciences Key Laboratory \\ of Bio-Medical Diagnostics, Suzhou \\ Institute of Biomedical Engineering \\ and Technology, Chinese Academy \\ of Sciences, Suzhou, ${ }^{4}$ Department \\ of Pharmacology, Nanomedicine \\ Engineering Laboratory of Jilin \\ Province, College of Basic Medical \\ Sciences, Jilin University, Changchun, \\ People's Republic of China
}

Correspondence: Dan Shao Chinese Academy of Sciences Key Laboratory of Bio-Medical Diagnostics, Suzhou Institute of Biomedical Engineering and Technology, Chinese Academy of Sciences, 88 Keling RD, Suzhou 215163, Jiangsu, People's Republic of China Email stanauagate@outlook.com

Yan-min Zhou

Department of Dental Implantology, Jilin Province Key Laboratory of Tooth Development and Bone Remodeling, School and Hospital of Stomatology, Jilin University, No. I500 Qinghua Road, Chaoyang District I3002I, People's Republic of China

Email zhouym1962@hotmail.com

\begin{abstract}
Combination of chlorhexidine ( $\mathrm{CHX})$ and silver ions could engender synergistic bactericidal effect and improve the bactericidal efficacy. It is highly desired to develop an efficient carrier for the antiseptics codelivery targeting infection foci with acidic microenvironment. In this work, monodisperse mesoporous silica nanoparticle (MSN) nanospheres were successfully developed as an ideal carrier for CHX and nanosilver codelivery through a facile and environmentally friendly method. The CHX-loaded, silver-decorated mesoporous silica nanoparticles (Ag-MSNs@,CHX) exhibited a pH-responsive release manner of CHX and silver ions simultaneously, leading to synergistically antibacterial effect against both grampositive Staphylococcus aureus and gram-negative Escherichia coli. Moreover, the effective antibacterial concentration of Ag-MSNs@CHX showed less cytotoxicity on normal cells. Given their synergistically bactericidal ability and good biocompatibility, these nanoantiseptics might have effective and broad clinical applications for bacterial infections.
\end{abstract}

Keywords: mesoporous silica nanoparticles, silver nanoparticles, chlorhexidine, $\mathrm{pH}$-responsive release, synergistic bactericidal activity, good biocompatibility

\section{Introduction}

Bacterial infections have been recognized as one of the most crucial health challenges worldwide, affecting millions of people annually. ${ }^{1,2}$ Up to date, a combination of antiseptics has recently become a common strategy for bacterial infections, which might reduce the ever-increasing risk of antibacterial resistance. ${ }^{3}$ Chlorhexidine (CHX) has been commonly used as a preferred antiseptic due to its quicker kill rate and broadspectrum biocide effectiveness with less risk for the occurrence of an opportunistic infection. ${ }^{4,5}$ Besides CHX, silver has received substantial attention for centuries, thanks to its effective bactericidal activity and good biocompatibility. ${ }^{6,7}$ In the past decade, a slew of silver-containing nanomaterials were fabricated..$^{8-12}$ On account of precisely controlled release of silver ions, these nanomaterials could kill the bacteria by increasing their membrane permeability and producing reactive oxygen species (ROS). ${ }^{13,14}$ Beyond these features, nanoscale silver with smaller size and high-surface area is capable of binding with bacteria. ${ }^{15,16}$ Importantly, recent studies demonstrated that the combination of CHX and silver ions could engender an obviously synergistic bactericidal effect and improve the bactericidal efficacy. ${ }^{17,18}$ Monteiro et al ${ }^{17}$ have demonstrated that silver nanoparticles (NPs) in combination with CHX may disrupt Candida biofilms, resulting in the prevention of resistance and improving the treatment of Candida-associated denture stomatitis. Ben-Knaz et al ${ }^{18}$ fabricated 
composite material containing $\mathrm{CHX}$ and metallic silver, which realized the synergetic bactericidal action toward the gram-negative Pseudomonas aeruginosa and the grampositive Staphylococcus epidermidis. Nevertheless, to exert maximum synergistic and minimal adverse effects of each component, a promising drug carrier is highly desirable for achieving the simultaneous delivery and stimulus-responsive release of $\mathrm{CHX}$ and silver ions.

In light of the integration of nanomaterials with biomedicine, the emergence of nanomedicine has promoted the development of novel carriers with localized delivery and sustained drug release manner. ${ }^{19-21}$ Mesoporous silica nanoparticles (MSNs) have been used as prominent nanocarriers for bactericidal agents owing to their superior physicochemical properties and biocompatibility. ${ }^{22-27}$
Conventionally, silver NPs are immobilized onto or embedded into MSNs to avoid the aggregation of silver NPs. ${ }^{28,29}$ Thus, these nanocarriers slowly release silver ions, leading to enhanced efficacy against bacteria. ${ }^{30,31}$ In addition, MSNs with entrapped CHX can exhibit sustainable $\mathrm{CHX}$ release behavior and inhibit bacterial growth while maintaining their surface integrity. ${ }^{32,33}$ However, studies on MSNbased $\mathrm{CHX} /$ silver codelivery have not been explored yet. Hence, we aimed to develop multifunctional MSNs that are capable of loading both $\mathrm{CHX}$ and silver with a $\mathrm{pH}$-triggered drug release for antibacterial applications.

Herein, nanosilver-decorated MSNs loaded with chlorhexidine (Ag-MSNs@CHX) were prepared through a facile and environmentally friendly method (Scheme 1). The resulting Ag-MSNs@CHX were used to determine the

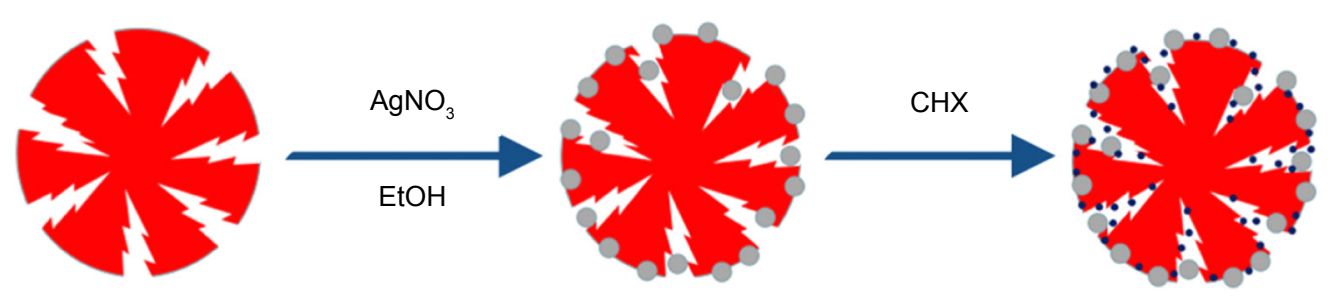

MSNs

Ag-MSNs

Ag-MSNs@CHX

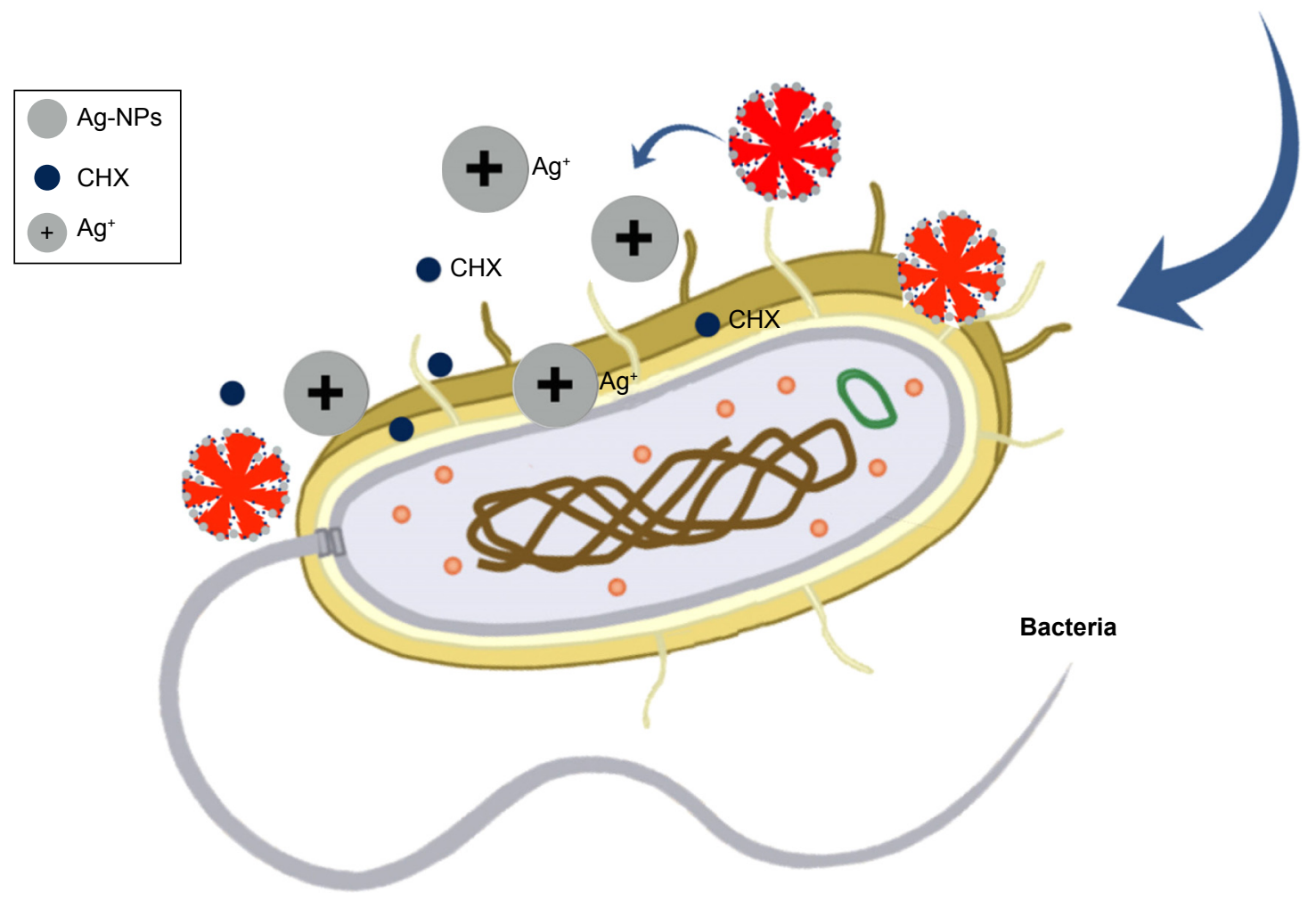

Scheme I Schematic representation of synthetic diagram for Ag-MSNs@CHX and their synergistic bactericidal effect.

Abbreviations: Ag-MSNs@vCHX, chlorhexidine-loaded, silver-decorated mesoporous silica nanoparticles; CHX, chlorhexidine; Ag-MSNs, silver-decorated mesoporous silica nanoparticles; MSNs, mesoporous silica nanoparticles. 
loading content and the $\mathrm{pH}$-responsive releasing profiles of $\mathrm{CHX}$ and silver ions. Of note, the bactericidal effect of AgMSNs@CHX was comprehensively investigated on both gram-positive Staphylococcus aureus and gram-negative Escherichia coli. Furthermore, the cytotoxicity of AgMSNs@CHX was also evaluated with normal cells. Given their synergistically bactericidal ability and good biocompatibility, these nanoantiseptics might have effective and broad clinical applications for bacterial infections.

\section{Materials and methods Materials}

CHX (99.5\%), tetraethyl orthosilicate (TEOS, 98\%), etyltrimethylammonium tosylate (CTAT, 98\%), triethanolamine $\left(\mathrm{TEAH}_{3}\right)$, and 3-aminopropyltriethoxysilane (APTES) were purchased from Sigma-Aldrich Co. (St Louis, MO, USA). Bis(3-triethoxysilyl propyl)disulfide (DIS) was purchased from Capatue Chemical Co., Ltd. (Nanjing, People's Republic of China). Silver nitrate $\left(\mathrm{AgNO}_{3}, 99.5 \%\right)$, hydrochloric acid (37\%), anhydrous ethanol, ammonium hydroxide $\left(\mathrm{NH}_{4} \mathrm{OH}, 28 \%\right)$, N,N-dimethylformamide (DMF), and dimethyl sulfoxide (DMSO) were purchased from Beijing Chemical Reagent Co. (Beijing, People's Republic of China). 3-(4,5-Di-methylthiazol-2-yl)-2,5-diphenyl tetrazolium bromide (MTT), RPMI-1640 medium, fetal bovine serum (FBS), penicillin, and streptomycin were obtained from Gibco (Carlsbad, CA, USA).

\section{Synthesis of Ag-MSNs}

The MSNs- $\mathrm{NH}_{2}$ were synthesized through a modified sol-gel method. In brief, $1.5 \mathrm{~g}$ of CTAT was first mixed with $0.5 \mathrm{~g}$ of $\mathrm{TEAH}_{3}$ in $100 \mathrm{~mL}$ of deionized water, and the mixture was stirred at $80^{\circ} \mathrm{C}$ for 1 hour. When the surfactant was completely dissolved, a mixture of $1.0 \mathrm{~g}$ of TEOS, $1.0 \mathrm{~g}$ of DIS, and $0.2 \mathrm{~g}$ of APTES was quickly added into the surfactant solution and reacted for another 3 hours at the same temperature. The synthesized MSNs- $\mathrm{NH}_{2}$ were collected and washed three times with ethanol. To remove the surfactant, the as-prepared MSNs$\mathrm{NH}_{2}$ were dissolved in $95 \mathrm{~mL}$ of ethanol and hydrochloric acid $(37 \%, 5 \mathrm{~mL})$ under ultrasonication, and then the mixture was stirred at $80^{\circ} \mathrm{C}$ for 12 hours. Products were thoroughly washed three times with ethanol and deionized water.

Nanosilver-decorated MSNs were synthesized through a facile ultrasonication-assisted method. ${ }^{31}$ In brief, $200 \mathrm{mg}$ of MSNs- $\mathrm{NH}_{2}$ was dissolved in $90 \mathrm{~mL}$ of deionized water under ultrasonic treatment for 1 hour. Then, the silver ammonia complex cation $\left(\left[\mathrm{Ag}\left(\mathrm{NH}_{3}\right)_{2}\right]^{+}\right)$was prepared by mixture of $9.0 \mathrm{~mL}$ of $5 \% \mathrm{AgNO}_{3}$ solution and $1 \mathrm{~mL}$ of an ammonium hydroxide $(28 \%)$. The $\left(\left[\mathrm{Ag}\left(\mathrm{NH}_{3}\right)_{2}\right]^{+}\right)$was added into the MSNs- $\mathrm{NH}_{2}$ solutions and reacted in the dark for 30 minutes under ultrasonication. The final product was centrifuged and washed three times with deionized water and stored in $10 \mathrm{~mL}$ deionized water.

\section{Characterization of Ag-MSNs}

Transmission electron microscopic images were measured through JEM-2100F transmission electron microscope (JEOL, Ltd., Japan) under $200 \mathrm{kV}$ accelerating voltage. Energy dispersive X-ray spectroscopy (EDX) was also performed using a JEM-2100F EDX instrument. The morphology of the Ag-MSNs and the bacteria were inspected using a scanning electron microscope (FESEM, S4800, Hitachi Co. Ltd., Tokyo, Japan). The mesoporous properties were determined by the Brunauer-Emmett-Teller (BET) method through Micromeritics ASAP2010 surface area analyzer. The pore diameter was measured from the adsorption branch of the isotherm by the BJH method. X-ray powder diffraction (XRD) investigation was carried out on a Rigaku X-ray diffractometer using $\mathrm{Cu} \mathrm{K} \alpha$ radiation. The size distribution and zeta potential were measured by Zetasizer (Nano ZS; Malvern Instruments, Malvern, UK). The silver content of the Ag-MSNs was measured via inductively coupled plasma mass spectrometer (ICP-MS) (Xseries II; Thermo Scientific, Waltham, MA, USA).

\section{Drug loading and the release of $\mathrm{CHX}$ and silver ions}

To assess the $\mathrm{pH}$-sensitive-based CHX release ability, AgMSNs were functionalized with carboxylate group according to our previous work. In brief, $100 \mathrm{mg}$ of as-prepared AgMSNs was dispersed in the $500 \mathrm{~mL}$ of DMF solution containing $2 \mathrm{wt} \%$ succinic anhydride and $1 \mathrm{~mL}$ of DMSO. The mixture was stirred at room temperature for 24 hours. After that, as-prepared Ag-MSNs-COOH were collected, washed, and dispersed in $10 \mathrm{~mL}$ of ethanol for drug loading.

For CHX loading, the CHX solution $(1.5 \mathrm{mg} / \mathrm{mL})$ was freshly prepared via dissolving $7.5 \mathrm{mg}$ of $\mathrm{CHX}$ in $5 \mathrm{~mL}$ of ethanol. Then, $5 \mathrm{~mL}$ of $\mathrm{Ag}-\mathrm{MSNs}-\mathrm{COOH}$ ethanol solution $(10 \mathrm{mg} / \mathrm{mL}$ ) was added to the CHX solution, the mixture was stirred at room temperature for 1 day. Finally, CHX-loaded Ag-MSNs were redispersed in water, and the amount of CHX was measured by UV-vis spectrophotometry at the wavelength of $254 \mathrm{~nm}$. The loading efficiency and drug-loading content were calculated according to our previous studies. ${ }^{25,26}$

To investigate the release behavior of CHX and silver ions, 100 mg of Ag-MSNs@CHX were dissolved in 100 mL 
of PBS solutions ( $\mathrm{pH}=7.4$ or 5.5) under ultrasonication. Then, the solution was transferred into a dialysis bag (molecular weight cutoff 5,000 ) on a shaking table at $37^{\circ} \mathrm{C}$ for 4 days. At each timed interval, the amounts of released $\mathrm{CHX}$ in the supernatant were detected through UV-vis spectrophotometry at the wavelength of $254 \mathrm{~nm}$, while the amounts of released silver ions were measured by ICP-MS.

\section{Bactericidal properties}

Standard strains of $S$. aureus and $E$. coli were obtained from the archival collection at the School and Hospital of Stomatology, Jilin University. The bacterial strains were cultivated at $37^{\circ} \mathrm{C}$ in Luria-Bertani (LB) medium on a shaker bed at $300 \mathrm{rpm}$. Gram-positive bacteria $S$. aureus and gramnegative bacteria $E$. coli were diluted with LB medium for further experiments.

To measure the bactericidal kinetics and minimum inhibitory concentration (MIC), Ag-MSNs@CHX with different concentrations $(50,25,12.5,6.25$, and $0 \mu \mathrm{g} / \mathrm{mL})$ were separately added into tubes containing $5 \mathrm{~mL}$ of bacterial cultures and shaken under appropriate conditions. At different time intervals, $100 \mu \mathrm{L}$ of medium was withdrawn from the tube and transferred to 96 -well plate to detect the optical density (OD) value at $600 \mathrm{~nm}$.

To determine the minimum bactericidal concentration (MBC) of Ag-MSNs@CHX, the formation of bacterial colonies was performed on the LB-agar growth plates. In brief, 50, 25, 12.5, 6.25, or $0 \mu \mathrm{g} / \mathrm{mL}$ of Ag-MSNs@CHX were each mixed with $1 \times 10^{5} \mathrm{CFU} / \mathrm{mL}$ of bacteria in LB-agar medium. Then, a total of $200 \mu \mathrm{L}$ of bacteria-NPs medium was plated on a single LB-agar growth plate and then incubated overnight at $37^{\circ} \mathrm{C}$. Colonies were observed after 24 hours, and digital images of each plate were captured.

To investigate the synergistic bactericidal effect, AgMSNs@CHX (25 $\mu \mathrm{g} / \mathrm{mL}), \mathrm{CHX}(2.65 \mu \mathrm{g} / \mathrm{mL}), \mathrm{AgNO}_{3}$ (1.325 $\mu \mathrm{g} / \mathrm{mL}), \operatorname{Ag}-\mathrm{MSNs}(25 \mu \mathrm{g} / \mathrm{mL})$, and MSNs $(25 \mu \mathrm{g} / \mathrm{mL})$ were incubated with $S$. aureus, while Ag-MSNs@CHX $(12.5 \mu \mathrm{g} / \mathrm{mL}), \mathrm{CHX}(1.325 \mu \mathrm{g} / \mathrm{mL}), \mathrm{AgNO}_{3}(0.6625 \mu \mathrm{g} / \mathrm{mL})$, Ag-MSNs $(12.5 \mu \mathrm{g} / \mathrm{mL})$, and MSNs $(12.5 \mu \mathrm{g} / \mathrm{mL})$ were incubated with $E$. coli. The $\mathrm{OD}_{600} \mathrm{~nm}$ was measured within tubes, and the growth of tested bacteria was observed via plates.

\section{Cytotoxicity assessment}

The mouse embryonic fibroblasts (NIH-3T3) and human umbilical vein endothelial cells (HUVECs) were cultured in RPMI-1640 medium supplemented with $10 \%$ (v/v) heatinactivated $\mathrm{FBS}$, penicillin $(100 \mathrm{U} / \mathrm{mL})$, and streptomycin $(100 \mu \mathrm{g} / \mathrm{mL})$ at $37^{\circ} \mathrm{C}$ under $5 \% \mathrm{CO}_{2}$. The in vitro cytotoxicity of Ag-MSNs@CHX against NIH-3T3 and HUVECs was assessed using traditional MTT assays. In brief, cell density was adjusted to be $5 \times 10^{3} / \mathrm{mL}$ and planted on 96 -well plate at a volume of $200 \mu \mathrm{L} / w e l l$. The Ag-MSNs@CHX, CHX, $\mathrm{AgNO}_{3}, \mathrm{Ag}-\mathrm{MSNs}$, and MSNs at various concentrations were added to the plates and incubated for 24 hours. Then, MTT solutions were added to the plates and incubated for another 2 hours at $37^{\circ} \mathrm{C}$. The OD value at $490 \mathrm{~nm}$ wavelength was measured, and the cell viability ratio was calculated.

\section{Statistical analysis}

The experimental results were analyzed with SPSS 19.0 statistical software. Representative data were expressed as $x \pm s$. The comparison among groups was conducted by using the least significant difference (LSD) method, with singlefactor analysis of variance (one-way ANOVA); $P<0.05$ was counted as significant difference; all experiment results were repeated at least three times.

\section{Results and discussion Synthesis and characterization of Ag-MSNs}

The uniform MSNs- $\mathrm{NH}_{2}$ were first functionalized with positively charged APS according to a one-pot method. Transmission electron microscopic and scanning electron microscopic images confirmed that the resulting MSNs were spherical NPs with an average diameter of $100 \mathrm{~nm}$ (Figure 1A and B). The growth of nanosilvers on the MSNs' surface was then achieved under ultrasonication by introducing silver ammonia complex cation $\left(\left[\mathrm{Ag}\left(\mathrm{NH}_{3}\right)_{2}\right]^{+}\right)$into the MSNs- $\mathrm{NH}_{2}$ suspension. During the process, the amino group acted as a bridge between the MSNs matrix and silver ions. To form nanosilver, the silver ions were reduced by amino group subsequently. As shown in Figure $1 \mathrm{C}$ and D, the average size of the Ag-MSNs was similar with the $\mathrm{MSNs}_{-} \mathrm{NH}_{2}$ nanospheres. A large number of small nanosilver dots were homogeneously distributed on the surface and pores of MSNs. It is worthwhile to note that sonication plays a crucial role in resulting such a high nanosilver decoration. According to several reports, sonication expedited the process of reduction reaction due to its high temperature and pressure. ${ }^{34,35}$ In addition, Ag-MSNs exhibited single peak and narrow size distribution with lower polydispersity index (PDI $=0.133$ ) (Figure S1), indicating their good stability in water. Therefore, the well-synthesized Ag-MSNs could be protected from aggregation and might release silver ions under environmental conditions.

The wide-angle XRD pattern of the obtained Ag-MSNs showed that the characteristic diffraction peaks at 38, 44, 

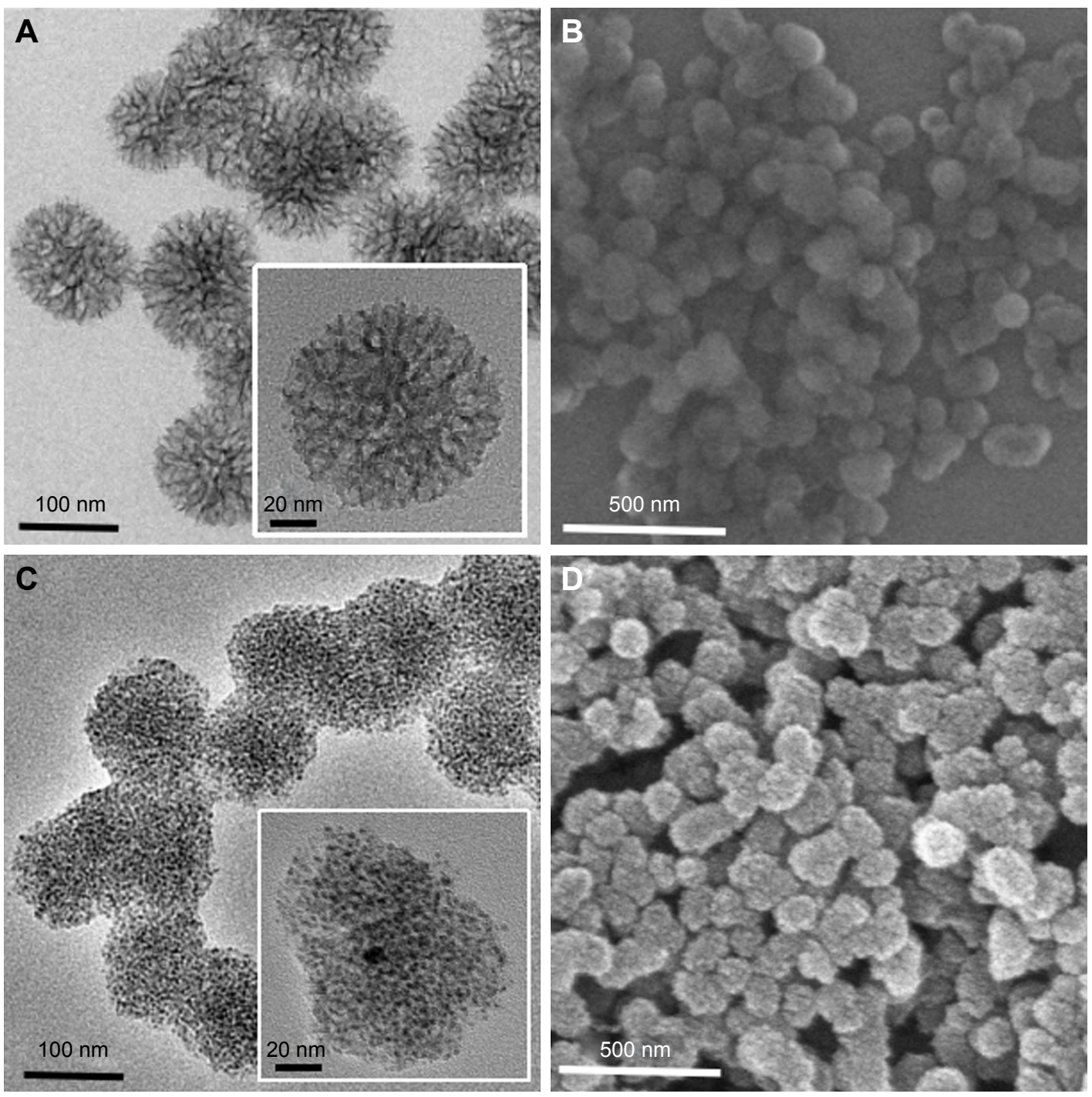

Figure I Morphology of Ag-MSNs.

Notes: TEM image of (A) MSNs and (C) Ag-MSNs. SEM image of (B) MSNs and (D) Ag-MSNs.

Abbreviations: Ag-MSNs, silver-decorated mesoporous silica nanoparticles; MSNs, mesoporous silica nanoparticles; SEM, scanning electron microscope; TEM, transmission electron microscope.

64, 77, and $82^{\circ}$ were (111), (200), (220), (311), and (222), correspondingly (Figure 2A). Meanwhile, the presence of silver nanodots was also further verified by energy-dispersive $\mathrm{X}$-ray (EDX) spectroscopy analysis, and the coexistence of $\mathrm{Si}, \mathrm{O}$, and Ag elements could be observed from Figure 2B. Mesoporous features of MSNs and Ag-MSNs were demonstrated by the nitrogen adsorption isotherm, which possessed a type IV isotherm (Figure 2C and D). The surface area, pore volume, and average pore diameter of Ag-MSNs were determined to be $359.1 \mathrm{~m}^{2} / \mathrm{g}, 0.91 \mathrm{~cm}^{3} / \mathrm{g}$, and $3.0 \mathrm{~nm}$, respectively, which were lower than $533.5 \mathrm{~m}^{2} / \mathrm{g}, 1.23 \mathrm{~cm}^{3} / \mathrm{g}$, and $5.6 \mathrm{~nm}$ of MSNs. These data were corroborated with the transmission electron microscopy (TEM) results and further demonstrated the presence of nanosilvers in the interior surface of MSNs. Although their mesoporous properties were affected by the anchored nanosilvers, Ag-MSNs still held promising potential in loading sufficient amount of $\mathrm{CHX}$.

\section{PH-responsive release of Ag-MSNs@ $\mathrm{CHX}$}

The ideal nanocarriers would bind to bacterial surfaces and rapidly release antiseptics or antibiotics in response to the environmental stimuli. ${ }^{36}$ To achieve $\mathrm{pH}$-responsive release of $\mathrm{CHX}$, we introduced a carboxylate functional group onto the pore's surface of the Ag-MSNs for loading positively charged CHX through electrostatic interaction (Figure S2). These obtained Ag-MSNs@CHX were also stable in both neutral and acid solutions (Figure S3). As revealed by UV-vis measurement, the loading efficiency and drug-loading content of CHX in the Ag-MSNs were $83.1 \pm 4.1$ and $10.6 \% \pm 1.9 \%$, 
A
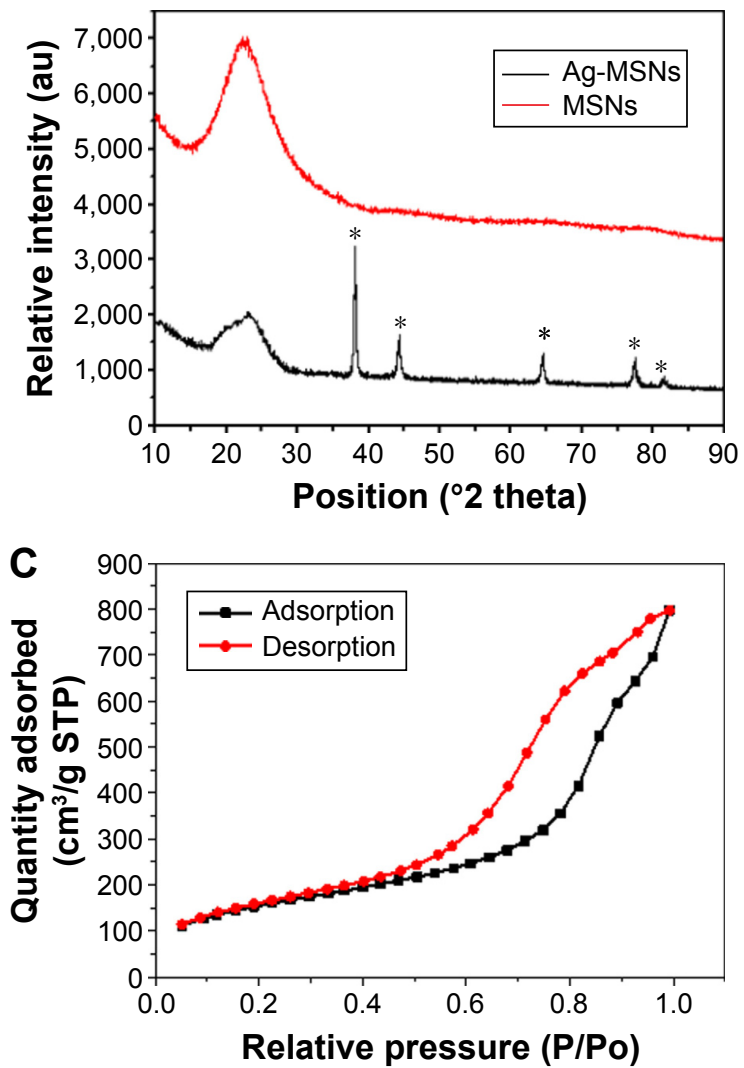

B
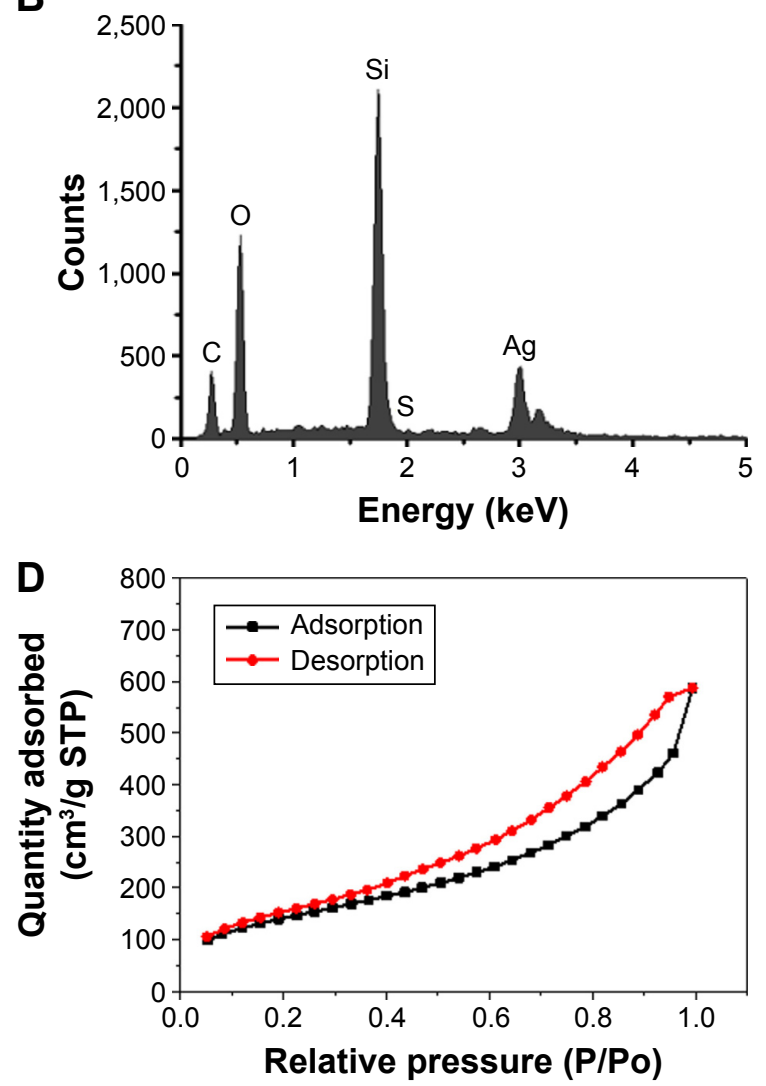

Figure 2 Characterization of Ag-MSNs.

Notes: (A) XRD patterns of the as-prepared MSNs and Ag-MSNs. (B) EDS spectra of Ag-MSNs. $\mathrm{N}_{2}$ sorption isotherms of (C) MSNs and (D) Ag-MSNs.

Abbreviations: MSNs, mesoporous silica nanoparticles; Ag-MSNs, silver-decorated mesoporous silica nanoparticles; XRD, X-ray powder diffraction; EDS, energy dispersive $\mathrm{X}$-ray spectrometer; STP, standard temperature and pressure; $\mathrm{P}$, absolute pressure; Po, saturation pressure.

respectively. It is well known that bacterial infection is accompanied by local decrease in $\mathrm{pH}$, which is induced by generation of several organic acids triggered by low-oxygen condition. ${ }^{37,38}$ Therefore, acidic microenvironments were used as a trigger for accelerated $\mathrm{CHX}$ release. As shown in Figure 3A, there was an initial burst in the first 12 hours. It is worth noting that more than $39 \%$ of $\mathrm{CHX}$ was released at $\mathrm{pH} 5.0$ compared with $18 \%$ of $\mathrm{CHX}$ released at $\mathrm{pH} 7.4$
A

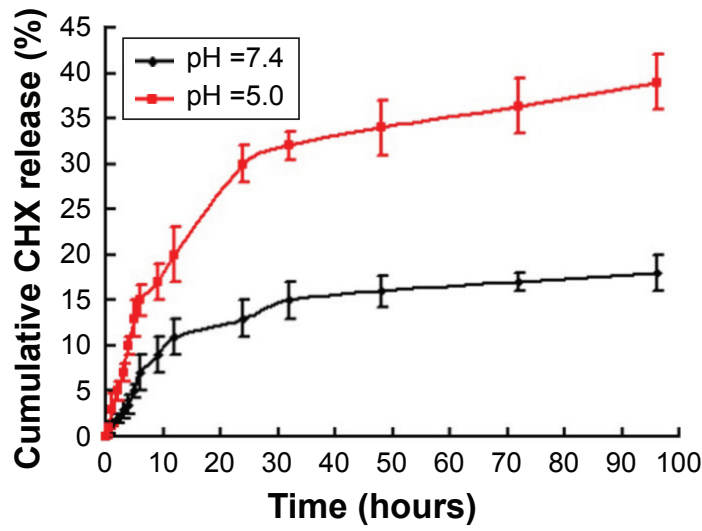

B

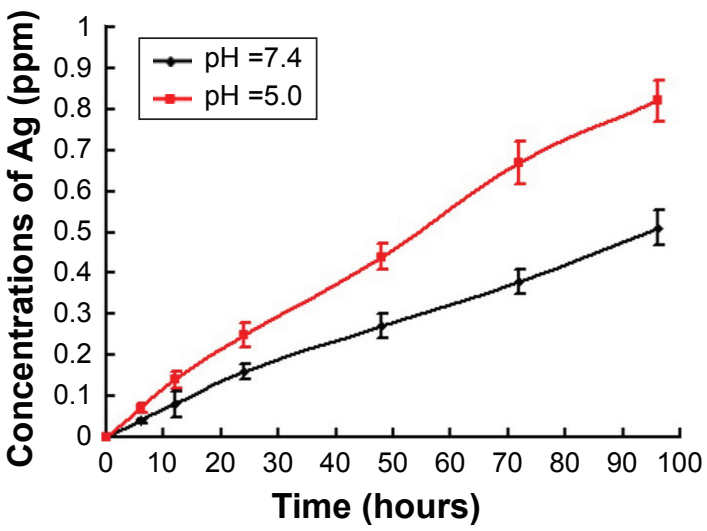

Figure 3 Release profiles of Ag-MSNs@CHX.

Notes: The $\mathrm{pH}$-dependent release profiles of $(\mathbf{A}) \mathrm{CHX}$ and $(\mathbf{B})$ silver ions from Ag-MSNs@CHX at pH=7.0 and 5.5. These data represent three separate experiments and are presented as mean values \pm SDs.

Abbreviations: Ag-MSNs@CHX, chlorhexidine-loaded, silver-decorated mesoporous silica nanoparticles; CHX, chlorhexidine; pH, potential of hydrogen; SD, standard deviation. 
within 96 hours. We ascribed this to the fact that the carboxyl functional groups were protonated and dissociated in response to the acidic environments, resulting in the preferential release of $\mathrm{CHX} .^{22,23}$ After the efficient therapy of a bacterial infection, the $\mathrm{pH}$ value of microenvironment returned to a physiological state. It contributed to the deprotonation of the carboxyl functional groups, which might block the release of $\mathrm{CHX}$.

The content of doped silver in Ag-MSNs was $~ 5.3 \%$, which was quantitatively determined by ICP-MS. Meanwhile, the release profiles of silver ions in the same condition are presented in Figure 3B, Ag-MSNs@CHX showed the similar sustained-release manner of silver ions over a course of 4 days in both acid and neutral conditions. More importantly, more silver ions would be released into acidic environment in comparison to neutral media, which was consistent with the $\mathrm{pH}$-dependent release fashion of nanosilvers reported by another group. ${ }^{39}$ This was because protonation could break surface Ag-O bonds, resulting in more silver ions release into solution at acidic than at neutral $\mathrm{pH} .{ }^{40}$ Taken together, these findings suggested that Ag-MSNs@CHX exhibited a capability of $\mathrm{pH}$-responsive release of both $\mathrm{CHX}$ and silver ions, which might enhance the bactericidal ability. Therefore, we proposed that Ag-MSNs@CHX with pH-sensitive antiseptic release behavior might enhance the antibacterial efficacy in acidic infection foci.

\section{Synergistically antibacterial effect of Ag-MSNs@CHX}

Since gram-positive bacteria $S$. aureus and gram-negative bacteria $E$. coli were two major candidates to induce bacterial infections, we used them as the model bacteria to investigate bactericidal activity of Ag-MSNs@CHX. ${ }^{25}$ The antibacterial kinetics of Ag-MSNs@CHX against S. aureus and $E$. coli in liquid LB media were evaluated by measuring the $\mathrm{OD}_{600}$ after culturing from 1 to 24 hours. As shown in Figure 4, the initial growth of $S$. aureus and $E$. coli was time dependently delayed along with the increased concentrations of Ag-MSNs@CHX. The growth inhibition was more noticeable for $E$. coli compared to $S$. aureus, as the nanoantiseptics were able to substantially reduce bacterial growth when the concentration of Ag-MSNs@CHX was below $12.5 \mu \mathrm{g} / \mathrm{mL}$. Additionally, dose-dependent inhibition of the Ag-MSNs@CHX in bacterial colonies was also demonstrated by using LB-agar media (Figure 5). The corresponding MIC and MBC of Ag-MSNs@CHX at 24 hours for $S$. aureus were $25 \mu \mathrm{g} / \mathrm{mL}$, which was higher than $E$. coli's $(12.5 \mu \mathrm{g} / \mathrm{mL})$. These findings were mainly due to the thicker and more compact wall of gram-positive bacteria than that of gram-negative bacteria. ${ }^{27}$ Furthermore, the scanning electron microscopic images revealed that plenty of Ag-MSNs@CHX adhered on the cell surface of bacteria after only 1-hour incubation (Figure 6). The results indicated that the positively charged Ag-MSNs@CHX (Figure S2) exhibited strong affinities toward both $S$. aureus and $E$. coli. Collectively, it was reasonable to claim that Ag-MSNs@CHX possessed an excellent bactericidal effect on both gram-positive bacteria and gram-negative bacteria. This outstanding bactericidal action of the Ag-MSNs@CHX was ascribed to the following reasons: first, the wide mesopores of MSNs offered chemical functionalization and permitted simultaneous hosting $\mathrm{CHX}$ and nanosilvers. Second, compared to larger silver NPs, the
A

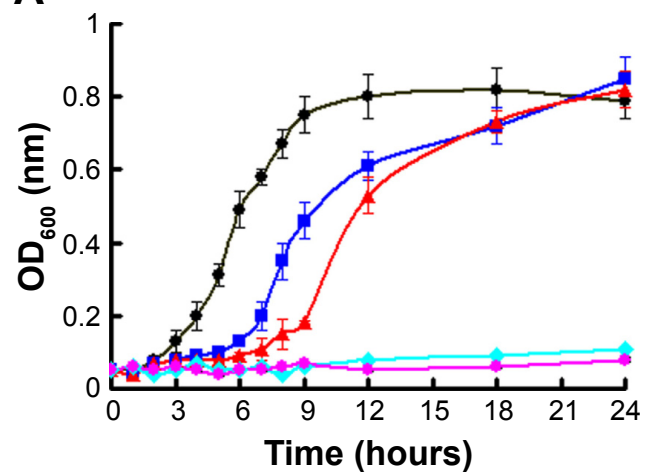

B

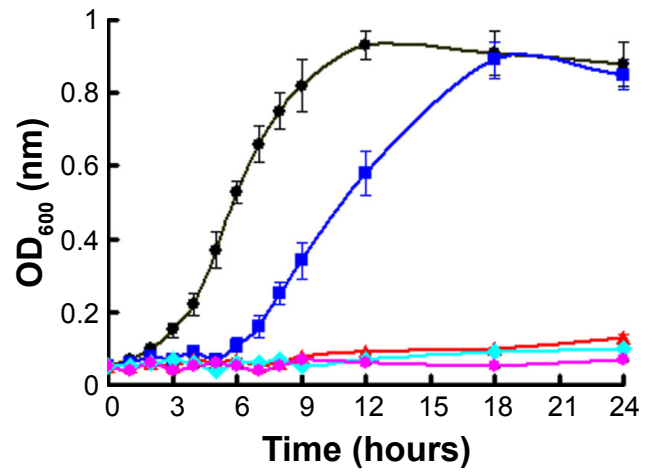

$\rightarrow-$ Con $\rightarrow-6.25 \mu \mathrm{g} / \mathrm{mL} \rightarrow 12.5 \mu \mathrm{g} / \mathrm{mL} \leadsto 25 \mu \mathrm{g} / \mathrm{mL} \rightarrow 50 \mu \mathrm{g} / \mathrm{mL}$

Figure 4 Bacterial growth inhibition with Ag-MSNs@CHX.

Notes: Bacterial growth curve of (A) S. aureus and (B) E. coli in LB liquid medium in the presence of Ag-MSNs@CHX with different concentrations. These data represent three separate experiments and are presented as mean values \pm SDs.

Abbreviations: Ag-MSNs@CHX, chlorhexidine-loaded, silver-decorated mesoporous silica nanoparticles; S. aureus, Staphylococcus aureus; E. coli, Escherichia coli; LB, lysogeny broth; SD, standard deviation; OD, optical density; con, control. 
A

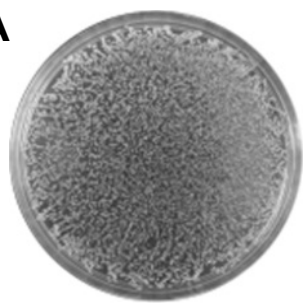

Con

B

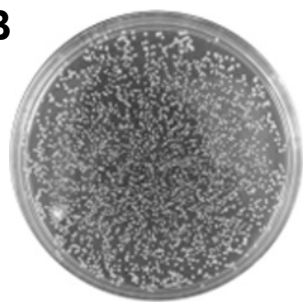

Con

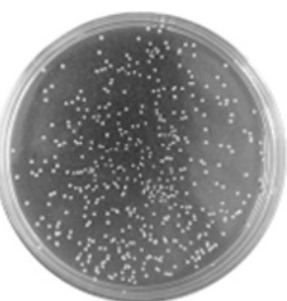

6.25

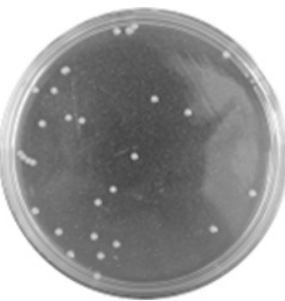

6.25

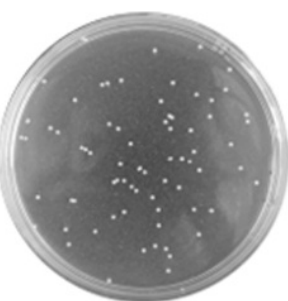

12.5

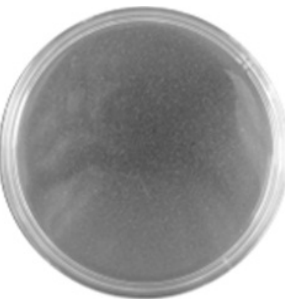

12.5

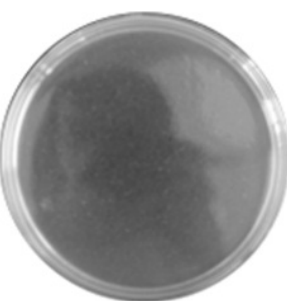

25

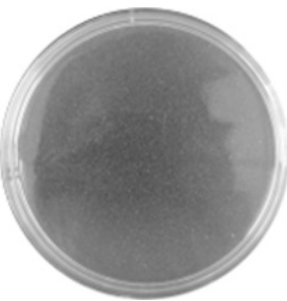

25

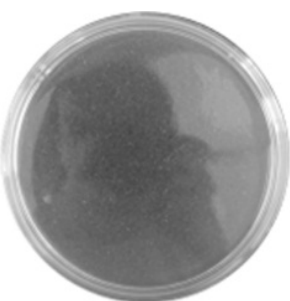

$50 \mu \mathrm{g} / \mathrm{mL}$

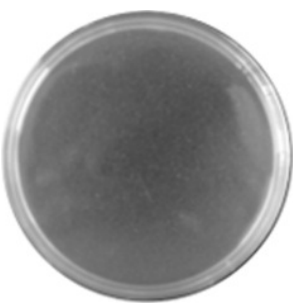

$50 \mu \mathrm{g} / \mathrm{mL}$

Figure 5 Bacteria colonies inhibition of $\mathrm{Ag}-\mathrm{MSNs} @ \mathrm{CHX}$.

Note: Photographs of LB-agar plates coated with (A) S. aureus and (B) E. coli when supplemented with different concentrations of Ag-MSNs@CHX.

Abbreviations: Ag-MSNs@CHX, chlorhexidine-loaded, silver-decorated mesoporous silica nanoparticles; LB, lysogeny broth; S. aureus, Staphylococcus aureus; E. coli, Escherichia coli; con, control.

silica matrix could prevent nanosilvers' aggregation and facilitate the dissolution of silver ions. ${ }^{41}$ Third, silver ions were able to release simultaneously with CHX under acid environment, realizing synergistically antibacterial effects.

To further determine the synergistic bactericidal effects of Ag-MSNs@CHX,we compared the antibacterial properties of Ag-MSNs@CHX with free CHX, $\mathrm{AgNO}_{3}$, and Ag-MSNs, which shared the same silver or CHX concentrations with Ag-MSNs@CHX. Formation of the bacterial colonies was examined through each particle or chemicalmedicated LB-agar media. As expected, the presence of Ag-MSNs@CHX could fully inhibit the formation of the bacterial colonies of $S$. aureus and E. coli. However, the bacterial colonies were obvious in plates containing equivalent concentration of $\mathrm{CHX}, \mathrm{AgNO}_{3}, \mathrm{Ag}-\mathrm{MSNs}$, and MSNs (Figure 7). The synergism of released CHX and silver ions might be attributed to the fact that CHX could disrupt the permeability and structures of bacterial cell membrane, which
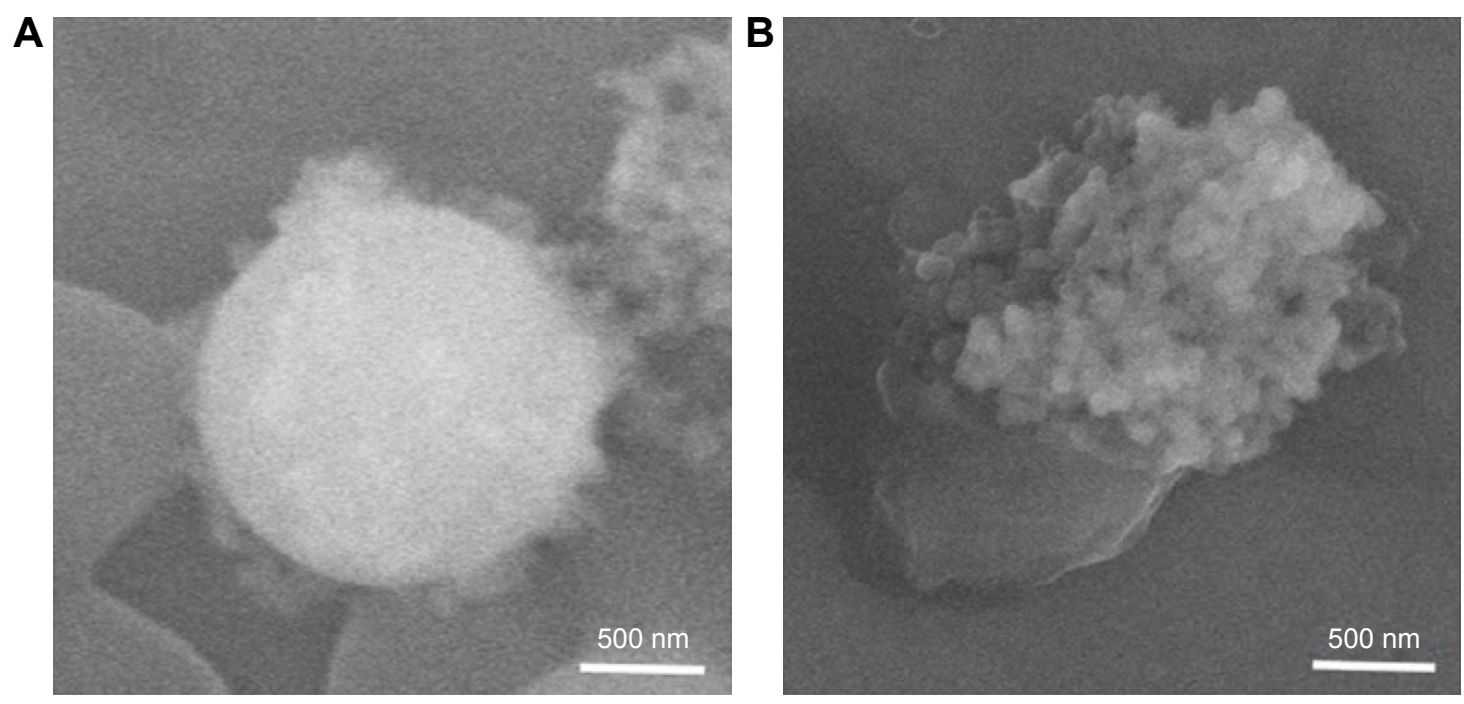

Figure 6 Interactions of Ag-MSNs@CHX with bacteria.

Note: Scanning electron microscopic images of Ag-MSNs after incubation with (A) S. aureus and (B) E. coli for 3 hours.

Abbreviations: Ag-MSNs@CHX, chlorhexidine-loaded, silver-decorated mesoporous silica nanoparticles; S. aureus, Staphylococcus aureus; E. coli, Escherichia coli. 
A

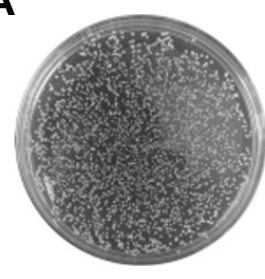

Control

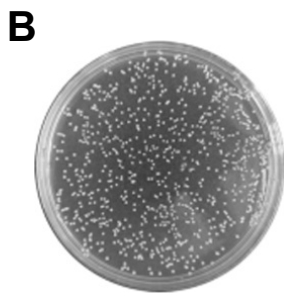

Control

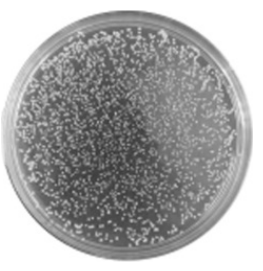

MSNs

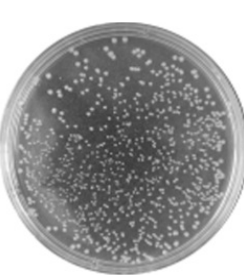

MSNs

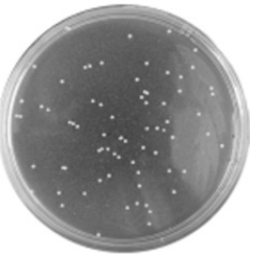

Ag-MSNs

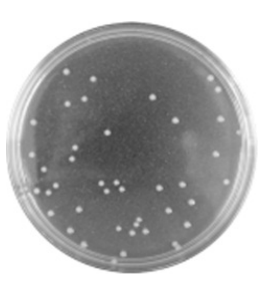

Ag-MSNs

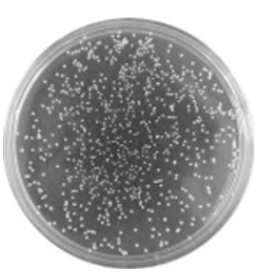

$\mathrm{AgNO}_{3}$

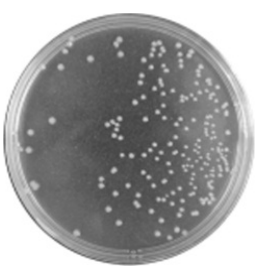

$\mathrm{AgNO}_{3}$

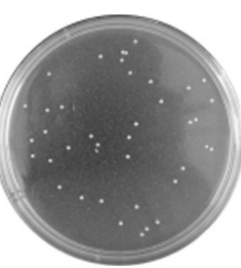

CHX

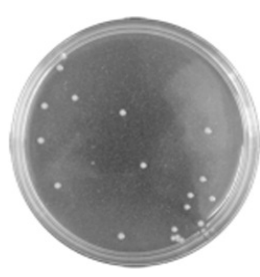

CHX

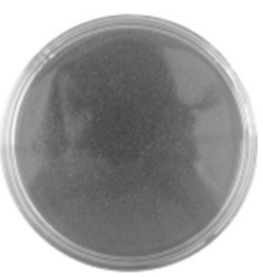

Ag-MSNs@CHX

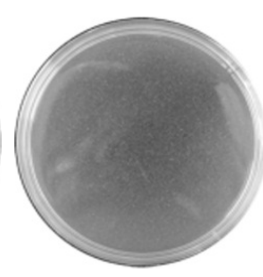

Ag-MSNs@CHX

Figure 7 Synergistical antibacterial effect of Ag-MSNs@CHX.

Note: Photographs of LB-agar plates coated with (A) S. aureus and (B) E. coli when supplemented with Ag-MSNs@CHX, CHX, AgNO, Ag-MSNs, and MSNs, respectively. Abbreviations: Ag-MSNs@CHX, chlorhexidine-loaded, silver-decorated mesoporous silica nanoparticles; LB, lysogeny broth; S. aureus, Staphylococcus aureus; E. coli, Escherichia coli; CHX, chlorhexidine; Ag-MSNs, silver-decorated mesoporous silica nanoparticles; MSNs, mesoporous silica nanoparticles.

might facilitate the uptake of silver ions into the bacteria. ${ }^{42}$ The silver ions could interact with the bacterial cell wall, DNA, enzymes, and membrane proteins, as well as induce ROS to kill the bacteria. ${ }^{12,43}$ Therefore, these Ag-MSNs@CHX nanocarriers presented synergistic antibacterial activities on both gram-positive bacteria and gram-negative bacteria.

\section{Cytotoxicity of Ag-MSNs@CHX}

Nanotoxicological aspect has been identified as the main concern of nanomedicine application for clinical therapeutics. ${ }^{44}$ It is well known that an excessive dose of silver NPs or CHX can trigger cell death, leading to unwanted side effects. ${ }^{45,46}$ We proposed that MSNs in our system are capable of reducing the silver ions release and possessing $\mathrm{pH}$-selective
CHX release in normal cells, resulting in lower toxicity. To determine whether Ag-MSNs@CHX exposure would impact the cell viability, we incubated mouse embryonic fibroblasts (NIH-3T3) and HUVEC with Ag-MSNs@, CHX (0-100 $\mu \mathrm{g} / \mathrm{mL})$ for 24 hours and detected cell death via MTT assay. Both NIH-3T3 and HUVECs were treated with increasing concentrations of Ag-MSNs@CHX up to $25 \mu \mathrm{g} / \mathrm{mL}$. The results showed similar survival rates to control group (Figure 8), identifying that our nanoantiseptics at even high concentrations were well tolerated. By contrast, $\mathrm{CHX}$ and $\mathrm{AgNO}_{3}$ groups (containing the same amount of CHX or silver compared with Ag-MSNs@CHX) exhibited significant cytotoxicity (Figure 9). We attributed this to the fact that slow-release behavior of Ag-MSNs@CHX in the
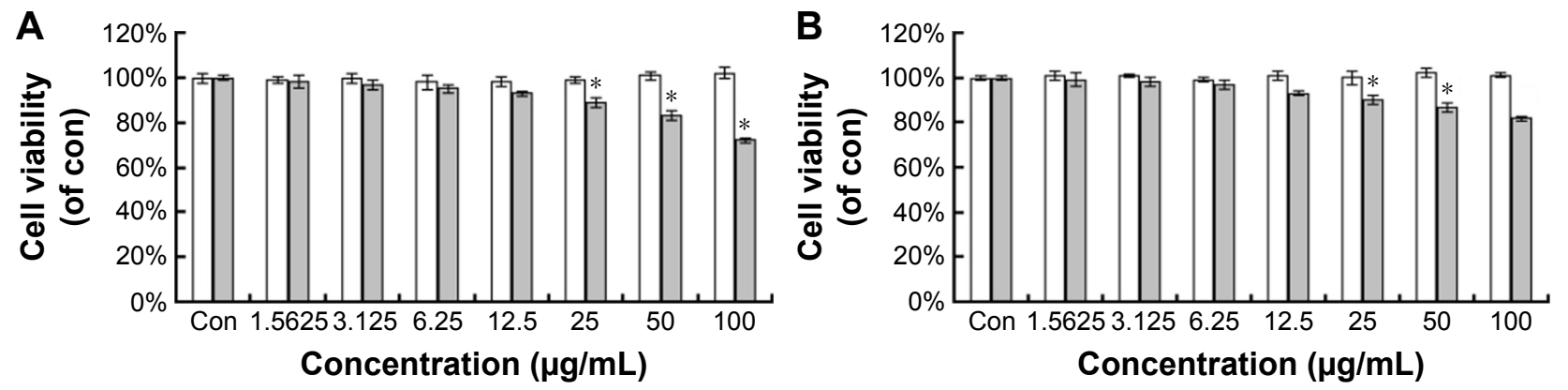

$\square$ MSNs $\square$ Ag-MSNs

Figure 8 Cytotoxicity of Ag-MSNs.

Notes: The cytotoxicity of MSNs and Ag-MSNs against (A) NIH-3T3 and (B) HUVECs at different levels of concentration after 24 hours. These data represent three separate experiments and are presented as mean values $\pm \mathrm{SDs}$. $* \mathrm{P}<0.05$ versus control group.

Abbreviations: Ag-MSNs, silver-decorated mesoporous silica nanoparticles; MSNs, mesoporous silica nanoparticles; HUVECs, human umbilical vein endothelial cells; $\mathrm{SD}$, standard deviation; con, control. 

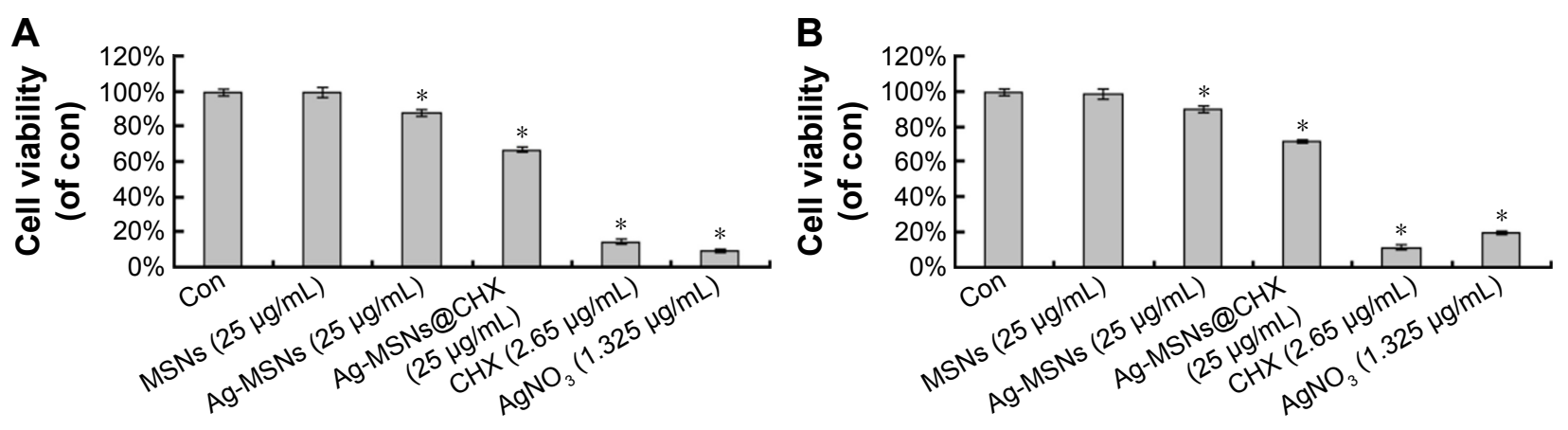

Figure 9 Cytotoxicity of Ag-MSNs@CHX.

Notes: The cytotoxicity of Ag-MSNs@CHX, CHX, AgNO, Ag-MSNs, and MSNs against (A) NIH-3T3 and (B) HUVECs at 24 hours. These data represent three separate experiments and are presented as mean values $\pm \mathrm{SDs}$. $* \mathrm{P}<0.05$ versus control group.

Abbreviations: Ag-MSNs@CHX, chlorhexidine-loaded, silver-decorated mesoporous silica nanoparticles; CHX, chlorhexidine; Ag-MSNs, silver-decorated mesoporous silica nanoparticles; MSNs, mesoporous silica nanoparticles; HUVECs, human umbilical vein endothelial cells; SD, standard deviation; con, control.

neutral microenvironment of normal cells was in line with our previous drug release data. ${ }^{22,23}$ These findings indicated that Ag-MSNs@CHX not only exhibited a synergistic bactericidal effect but also had higher biocompatibility than free $\mathrm{CHX}$ or silver ions.

\section{Conclusion}

Monodisperse MSNs nanospheres were successfully developed as an ideal carrier for codelivery of CHX and nanosilver through a facile and environmentally friendly method. The as-formed nanoantiseptics with high-density and welldistributed silver nanodots exhibited a $\mathrm{pH}$-responsive release manner of both CHX and silver ions simultaneously. Thus, Ag-MSNs@CHX possessed excellent bactericidal activity on gram-positive bacteria $S$. aureus and gram-negative bacteria E. coli at a low concentration, as well as good biocompatibility on normal cells. More importantly, the synergistic inhibitory effect of Ag-MSNs@CHX toward both $S$. aureus and $E$. coli was demonstrated. To this end, our findings lay the groundwork for exploiting Ag-MSNs@CHX as efficient and safe nanoantiseptics for the treatment of bacterial infections in the future.

\section{Acknowledgments}

This work was supported by the National Natural Science Foundation of China (81320108011 and 81601609), Science and Technology Development Program of Jilin Province (20140311004YY), Development and Reform Commission Program of Jilin Province (2014G075-1), Doctoral Fund of Ministry of Education of China (20120061110077), and the Graduate Innovation Fund of Jilin University (2015043).

\section{Disclosure}

The authors report no conflicts of interest in this work.

\section{References}

1. Munson EL, Diekema DJ, Beekmann SE, Chapin KC, Doern GV. Detection and treatment of bloodstream infection: laboratory reporting and antimicrobial management. J Clin Microbiol. 2003;41(1):495-497.

2. Grant SS, Hung DT. Persistent bacterial infections, antibiotic tolerance, and the oxidative stress response. Virulence. 2013;4(4):273-283.

3. Percival SL, Finnegan S, Donelli G, Vuotto C, Rimmer S, Lipsky BA. Antiseptics for treating infected wounds: efficacy on biofilms and effect of pH. Crit Rev Microbiol. 2016;42(2):293-309.

4. Chlebicki MP, Safdar N, O’Horo JC, Maki DG. Preoperative chlorhexidine shower or bath for prevention of surgical site infection: a meta-analysis. Am J Infect Control. 2013;41(2):167-173.

5. Macias JH, Arreguin V, Munoz JM, Alvarez JA, Mosqueda JL, Macias AE. Chlorhexidine is a better antiseptic than povidone iodine and sodium hypochlorite because of its substantive effect. Am J Infect Control. 2013;41(7):634-637.

6. Chernousova S, Epple M. Silver as antibacterial agent: ion, nanoparticle, and metal. Angew Chem Int Ed. 2013;52(6):1636-1653.

7. Franci G, Falanga A, Galdiero S, et al. Silver nanoparticles as potential antibacterial agents. Molecules. 2015;20(5):8856-8874.

8. Ahamed M, Alsalhi MS, Siddiqui M. Silver nanoparticle applications and human health. Clin Chim Acta. 2010;411(23):1841-1848.

9. Sharma VK, Yngard RA, Lin Y. Silver nanoparticles: green synthesis and their antimicrobial activities. Adv Colloid Interface Sci. 2009; 145(1):83-96.

10. Meng M, He H, Xiao J, Zhao P, Xie J, Lu Z. Controllable in situ synthesis of silver nanoparticles on multilayered film-coated silk fibers for antibacterial application. J Colloid Interface Sci. 2016;461:369-375.

11. Lu Z, Xiao J, Wang Y, Meng M. In situ synthesis of silver nanoparticles uniformly distributed on polydopamine-coated silk fibers for antibacterial application. J Colloid Interface Sci. 2015;452:8-14.

12. Guo L, Yuan W, Lu Z, et al. Polymer/nanosilver composite coatings for antibacterial applications. Colloids Surf A Physicochem Eng Asp. 2013; 439:69-83.

13. Rizzello L, Pompa PP. Nanosilver-based antibacterial drugs and devices: mechanisms, methodological drawbacks, and guidelines. Chem Soc Rev. 2014;43(5):1501-1518.

14. Agnihotri S, Mukherji S, Mukherji S. Size-controlled silver nanoparticles synthesized over the range 5-100 $\mathrm{nm}$ using the same protocol and their antibacterial efficacy. RSC Adv. 2014;4(8):3974-3983.

15. Sondi I, Salopek-Sondi B. Silver nanoparticles as antimicrobial agent: a case study on E. coli as a model for Gram-negative bacteria. J Colloid Interface Sci. 2004;275(1):177-182.

16. Wan G, Ruan L, Yin Y, Yang T, Ge M, Cheng X. Effects of silver nanoparticles in combination with antibiotics on the resistant bacteria Acinetobacter baumannii. Int J Nanomedicine. 2016;11:3789. 
17. Monteiro DR, Silva S, Negri M, et al. Antifungal activity of silver nanoparticles in combination with nystatin and chlorhexidine digluconate against Candida albicans and Candida glabrata biofilms. Mycoses. 2013;56(6):672-680.

18. Ben-Knaz R, Pedahzur R, Avnir D. Bioactive doped metals: high synergism in the bactericidal activity of chlorhexidine@ silver towards wound pathogenic bacteria. RSC Adv. 2013;3(21):8009-8015.

19. Campoccia D, Montanaro L, Arciola CR. A review of the clinical implications of anti-infective biomaterials and infection-resistant surfaces Biomaterials. 2013;34(33):8018-8029.

20. Forier K, Raemdonck K, De Smedt SC, Demeester J, Coenye T, Braeckmans K. Lipid and polymer nanoparticles for drug delivery to bacterial biofilms. J Control Release. 2014;190:607-623.

21. Niemirowicz K, Piktel E, Wilczewska AZ, et al. Core-shell magnetic nanoparticles display synergistic antibacterial effects against Pseudomonas aeruginosa and Staphylococcus aureus when combined with cathelicidin 11-37 or selected ceragenins. Int J Nanomedicine. 2016;11:5443.

22. Shao D, Li J, Zheng X, et al. Janus "nano-bullets" for magnetic targeting liver cancer chemotherapy. Biomaterials. 2016;100:118-133.

23. Shao D, Zhang X, Liu W, et al. Janus silver-mesoporous silica nanocarriers for SERS traceable and $\mathrm{pH}$-sensitive drug delivery in cancer therapy. ACS Appl Mater Interfaces. 2016;8(7):4303-4308.

24. Wang Z, Wang Y, Lu M, et al. Janus Au-mesoporous silica nanocarriers for chemo-photothermal treatment of liver cancer cells. RSC Adv. 2015;86(6):1548-1553.

25. Chang Z, Wang Z, Lu M, et al. Magnetic Janus nanorods for efficient capture, separation and elimination of bacteria. RSC Adv. 2017;7(6): 3550-3553.

26. Wang J, Wu G, Liu X, Sun G, Li D, Wei H. A decomposable silicabased antibacterial coating for percutaneous titanium implant. Int $J$ Nanomedicine. 2017;12:371.

27. Liu G, Li Q, Ni W, et al. Cytotoxicity of various types of goldmesoporous silica nanoparticles in human breast cancer cells. Int $J$ Nanomedicine. 2015;10:6075.

28. Wang Y, Ding X, Chen Y, et al. Antibiotic-loaded, silver coreembedded mesoporous silica nanovehicles as a synergistic antibacterial agent for the treatment of drug-resistant infections. Biomaterials. 2016;101:207-216.

29. Tian Y, Qi J, Zhang W, Cai Q, Jiang X. Facile, one-pot synthesis, and antibacterial activity of mesoporous silica nanoparticles decorated with well-dispersed silver nanoparticles. ACS Appl Mater Interfaces. 2014;6(15):12038-12045.

30. Zhang L, Luo Q, Zhang F, et al. High-performance magnetic antimicrobial Janus nanorods decorated with Ag nanoparticles. J Mater Chem. 2012;22(45):23741-23744.

31. Karaman DŞ, Sarwar S, Desai D, et al. Shape engineering boosts antibacterial activity of chitosan coated mesoporous silica nanoparticle doped with silver: a mechanistic investigation. J Mater Chem B. 2016; 4(19):3292-3304.
32. Zhang J, Wu R, Fan Y, et al. Antibacterial dental composites with chlorhexidine and mesoporous silica. J Dent Res. 2014;93(12): 1283-1289.

33. Moritz M, Geszke-Moritz M. Mesoporous silica materials with different structures as the carriers for antimicrobial agent. Modeling of chlorhexidine adsorption and release. Appl Surf Sci. 2015;356:1327-1340.

34. Chen S, Xu H, Xu H, et al. A facile ultrasonication assisted method for Fe3O4@SiO2-Ag nanospheres with excellent antibacterial activity. Dalton Trans. 2015;44(19):9140-9148.

35. Hui K, Hui K, Dinh D, et al. Green synthesis of dimension-controlled silver nanoparticle-graphene oxide with in situ ultrasonication. Acta Mater. 2014;64:326-332.

36. Mura S, Nicolas J, Couvreur P. Stimuli-responsive nanocarriers for drug delivery. Nat Mater. 2013;12(11):991-1003.

37. Fuchs S, Pané-Farré J, Kohler C, Hecker M, Engelmann S. Anaerobic gene expression in Staphylococcus aureus. J Bacteriol. 2007;189(11): 4275-4289.

38. Kuthati Y, Kankala RK, Lin S-X, Weng C-F, Lee C-H. pH-triggered controllable release of silver-indole-3 acetic acid complexes from mesoporous silica nanoparticles (IBN-4) for effectively killing malignant bacteria. Mol Pharm. 2015;12(7):2289-2304.

39. Peretyazhko TS, Zhang Q, Colvin VL. Size-controlled dissolution of silver nanoparticles at neutral and acidic $\mathrm{pH}$ conditions: kinetics and size changes. Environ Sci Technol. 2014;48(20):11954-11961.

40. Axson JL, Stark DI, Bondy AL, et al. Rapid kinetics of size and $\mathrm{pH}$-dependent dissolution and aggregation of silver nanoparticles in simulated gastric fluid. J Phys Chem C. 2015;119(35):20632-20641.

41. Gu G, Xu J, Wu Y, Chen M, Wu L. Synthesis and antibacterial property of hollow $\mathrm{SiO} 2 / \mathrm{Ag}$ nanocomposite spheres. J Colloid Interface Sci. 2011;359(2):327-333.

42. Lim KS, Kam PCA. Chlorhexidine-pharmacology and clinical applications. Anaesth Intensive Care. 2008;36(4):502.

43. Eckhardt S, Brunetto PS, Gagnon J, et al. Nanobio silver: its interactions with peptides and bacteria, and its uses in medicine. Chem Rev. 2013;113(7):4708-4754.

44. Hofmann-Amtenbrink M, Grainger D, Hofmann H. Nanoparticles in medicine: current challenges facing inorganic nanoparticle toxicity assessments and standardizations. Nanomedicine. 2015;11(7):1689-1694.

45. Lee Y, Cheng F, Chiu H, et al. Cytotoxicity, oxidative stress, apoptosis and the autophagic effects of silver nanoparticles in mouse embryonic fibroblasts. Biomaterials. 2014;35(16):4706-4715.

46. Li Y, Kuan Y, Lee T, et al. Assessment of the cytotoxicity of chlorhexidine by employing an in vitro mammalian test system. J Dent Sci. 2014; $9(2): 130-135$. 


\section{Supplementary materials}
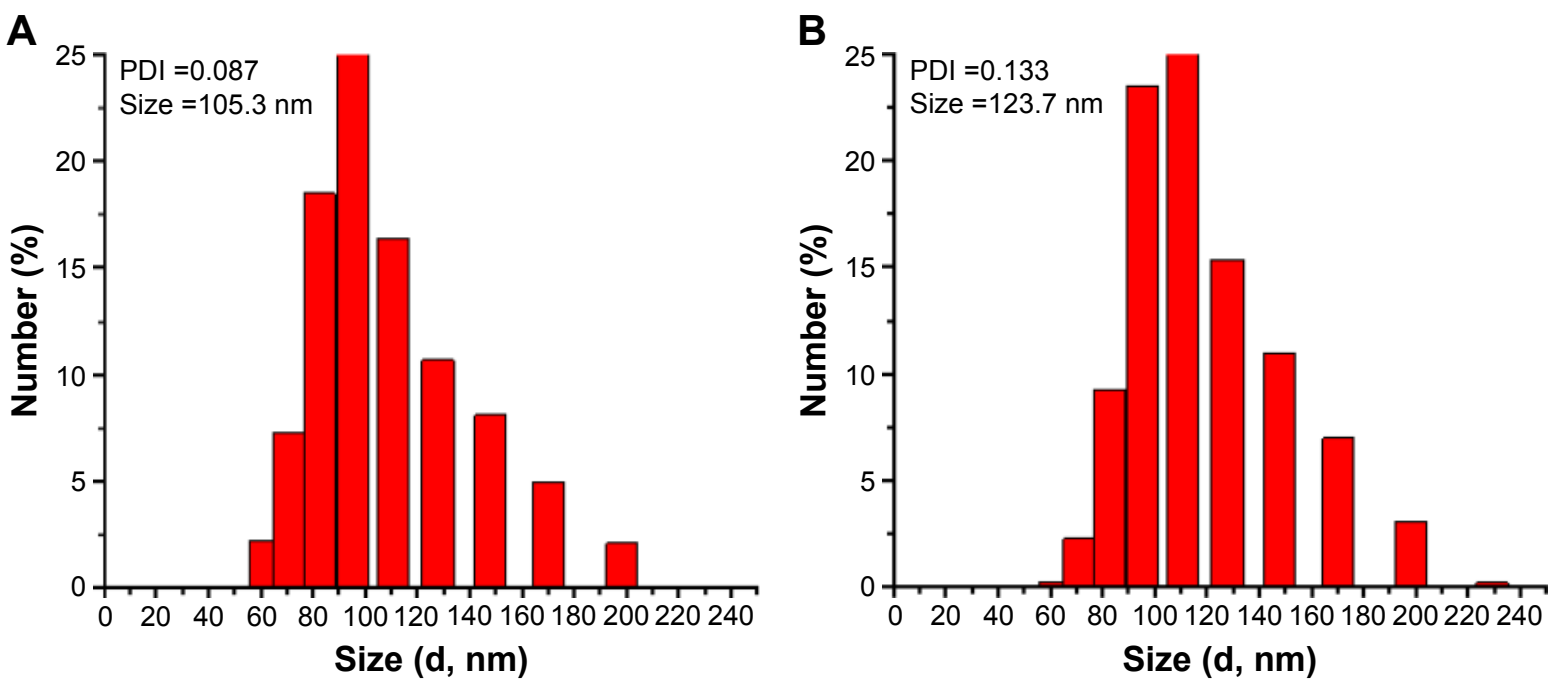

Figure SI Hydrodynamic diameter distribution of (A) MSNs and (B) Ag-MSNs in water.

Abbreviations: MSNs, mesoporous silica nanoparticles; Ag-MSNs, silver-decorated mesoporous silica nanoparticles; PDI, polydispersity index.

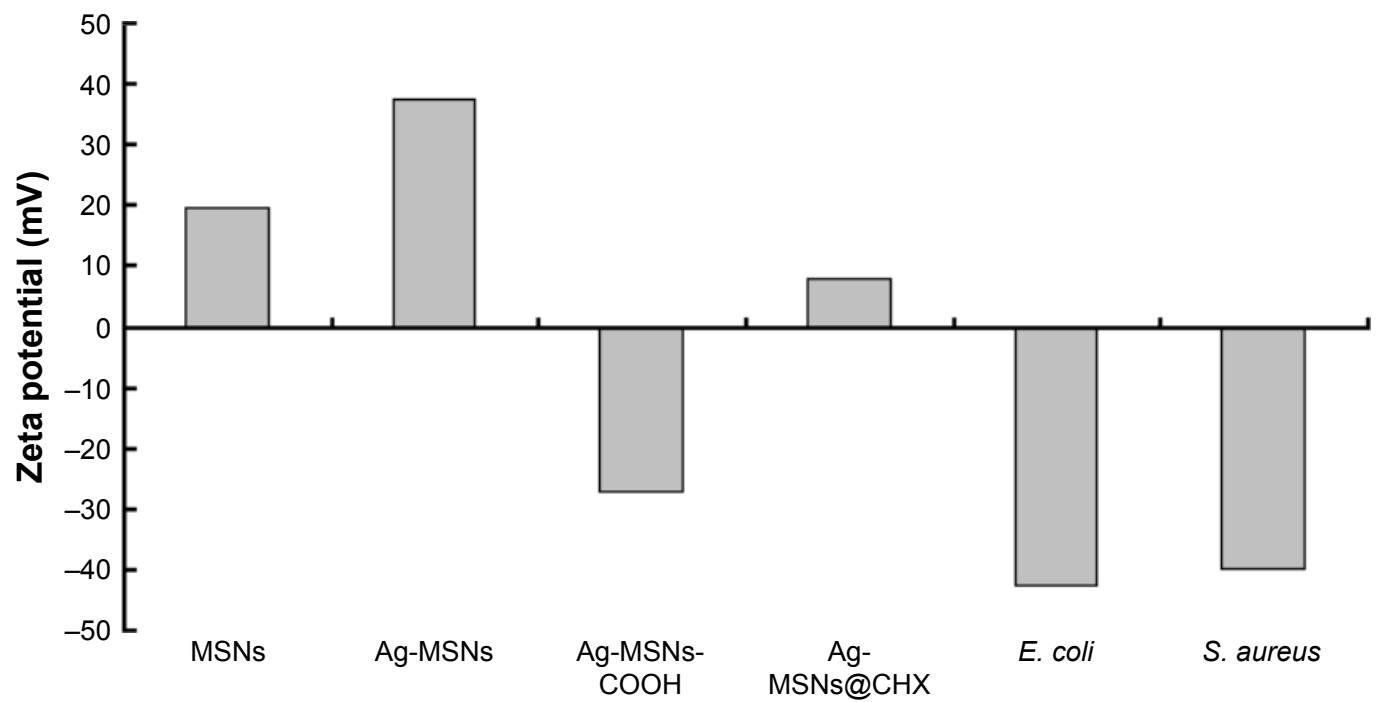

Figure S2 Zeta potential of MSNs, Ag-MSNs, Ag-MSNs-COOH, Ag-MSNs@CHX, and bacteria in water.

Abbreviations: MSNs, mesoporous silica nanoparticles; Ag-MSNs, silver-decorated mesoporous silica nanoparticles; CHX, chlorhexidine; Ag-MSNs@CHX, chlorhexidineloaded, silver-decorated mesoporous silica nanoparticles; S. aureus, Staphylococcus aureus; E. coli, Escherichia coli. 
A

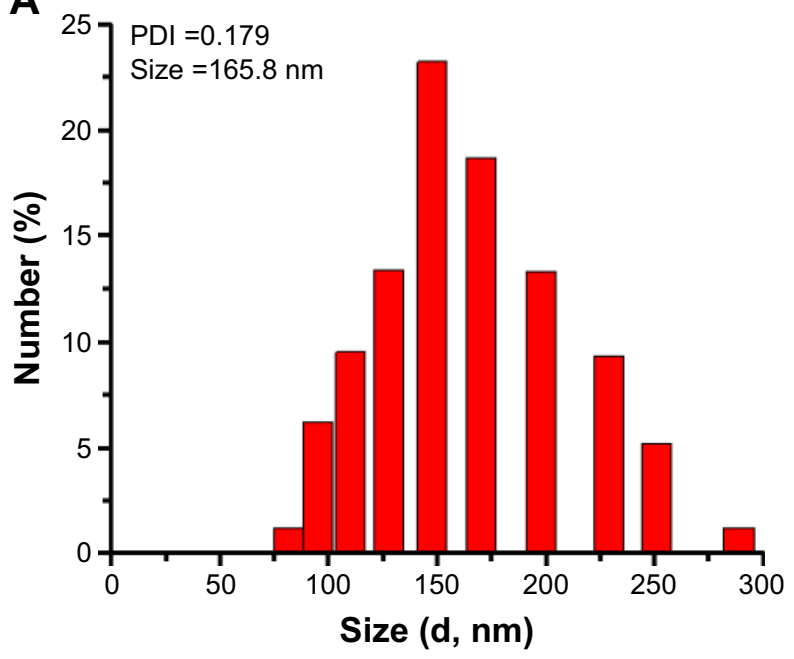

B

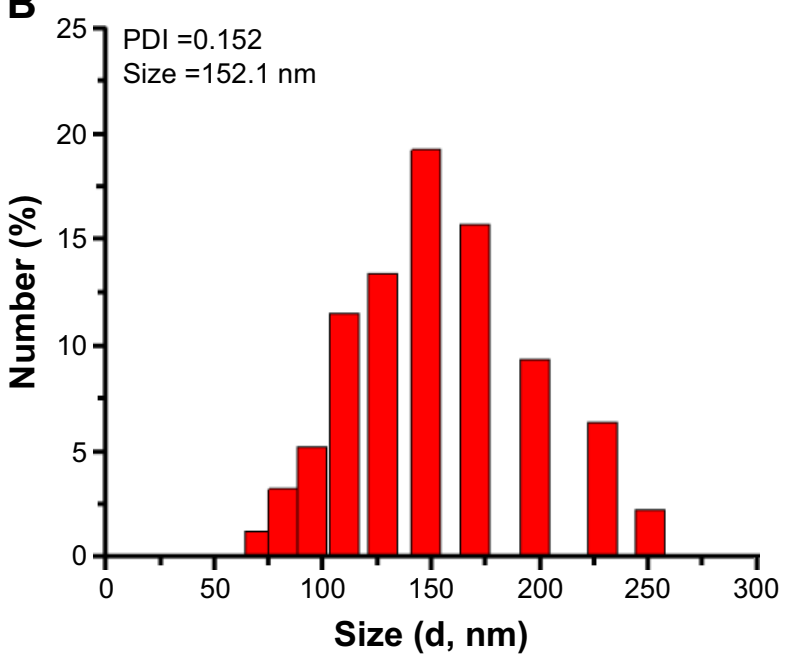

Figure S3 Hydrodynamic diameter distribution of Ag-MSNs@CHX in $(\mathbf{A}) \mathrm{pH}=7.4$ and $(\mathbf{B}) \mathrm{pH}=5.0$ of water.

Abbreviations: Ag-MSNs@CHX, chlorhexidine-loaded, silver-decorated mesoporous silica nanoparticles; PDI, polydispersity index.

\section{Publish your work in this journal}

The International Journal of Nanomedicine is an international, peerreviewed journal focusing on the application of nanotechnology in diagnostics, therapeutics, and drug delivery systems throughout the biomedical field. This journal is indexed on PubMed Central, MedLine, CAS, SciSearch ${ }^{\circledR}$, Current Contents ${ }^{\circledR} /$ Clinical Medicine,
Journal Citation Reports/Science Edition, EMBase, Scopus and the Elsevier Bibliographic databases. The manuscript management system is completely online and includes a very quick and fair peer-review system, which is all easy to use. Visit http://www.dovepress.com/ testimonials.php to read real quotes from published authors. 